\title{
PLATE FIXATION OF OPEN FRACTURES OF THE TIBIA
}

\author{
R. P. Clifford, C. G. BeAuchamp, J. F. Kellam, J. K. WebB, M. TILE \\ From the University Hospital, Nottingham, and Sunnybrook Medical Centre, Toronto
}

\begin{abstract}
The results of immediate plate fixation of 97 open fractures of the tibial shaft in 95 patients are reported. Significant joint stifiness occurred in $11.4 \%$ and angular malunion of greater than $5^{\circ}$ in any plane was seen in $3.1 \%$. The infection rate was $10.3 \%$. However, even in those cases which develop delayed union or other complications, plate fixation of open fractures can produce excellent recovery of limb function.
\end{abstract}

The subcutaneous and unprotected position of the tibia renders it particularly vulnerable and accounts for its common presentation as an open fracture. These injuries are frequently severe and inappropriate treatment may have disastrous results (Hicks 1964). Few would argue as to the importance of exemplary management of the soft tissues, but the treatment of the bony injury remains controversial. Generally, internal fixation of open tibial fractures remains unpopular, whereas external fixation, traction via the calcaneum, and cast immobilisation are advocated and widely used.

\section{MATERIALS AND METHODS}

We have reviewed the notes and radiographs of 110 consecutive displaced open tibial shaft fractures treated by immediate plate fixation over a four-year period at the Queen's Medical Centre, Nottingham and Sunnybrook Medical Centre, Toronto. Five of the patients died early from multiple injuries, two underwent early amputation following failed vascular reconstruction and six failed to return for clinical review, leaving 97 fractures in 95 patients to be reviewed. All these patients had clinical and radiographic follow-up ranging from one to five years. Eighty-one patients were male and 14 female;

R. P. Clifford, FRCS, Consultant Orthopaedic Surgeon Department of Orthopaedic Surgery, The General Hospital, Gloucester Street, St. Helier, Jersey, Channel Islands.

C. G. Beauchamp, FRCS, Consultant Orthopaedic Surgeon Chesterfield and North Derbyshire Royal Hospital, Chesterfield, Derbyshire S44 5BL, England.

J. K. Webb, FRCS, Consultant Orthopaedic Surgeon Queen's Medical Centre, Clifton Boulevard, Nottingham NG7 2UH, England.

J. F. Kellam, FRCS (C), Orthopaedic Surgeon

M. Tile, FRCS (C), Chief of Surgery

Sunnybrook Medical Centre, 2075, Bayview Avenue, Toronto, Ontario, Canada M4N 3MS.

Correspondence should be sent to Mr R. P. Clifford.

(C) 1988 British Editorial Society of Bone and Joint Surgery 0301-620X/88/4114\$2.00

J Bone Joint Surg [Br] 1988;70-B:644-8. their average age was 29.2 years with a range from 16 to 93 years (Fig. 1).

Seventy-seven patients had been injured in road traffic accidents and eight in heavy industrial accidents (Table I). Forty-six patients suffered multiple injuries, two had bilateral tibial fractures and 47 had single fractures. The fibula was fractured in all but three cases. The middle third of the tibia was involved in 48 cases,

Table I. Cause of injury in 95 patients with open tibial fractures

\begin{tabular}{lllr}
\hline Road traffic accident & 77 & $\begin{array}{l}\text { Motorcycle } \\
\text { Car or lorry }\end{array}$ & 55 \\
& & $\begin{array}{l}\text { Cycle } \\
\text { Pedestrian }\end{array}$ & 3 \\
& & \\
Industrial accident & 8 & \\
Sports injury & 6 & \\
Fall at home & 4 & \\
\hline
\end{tabular}

Table II. Characteristic features of 97 open tibial fractures

\begin{tabular}{lll}
\hline & & Number \\
\hline Site & Upper third & 11 \\
& Middle third & 48 \\
& Lower third & 25 \\
& Segmental & 13 \\
Type & Transverse & 12 \\
& Spiral or oblique & 12 \\
& Butterfly fragment & 16 \\
& Comminuted & 44 \\
Displacement related & Segmental & 13 \\
to shaft diameter & Over one & 26 \\
& One & 33 \\
& Three-quarters & 15 \\
& Half & 17 \\
& Quarter & 6 \\
\hline
\end{tabular}

while 73 had butterfly, comminuted or segmental fractures and 59 fractures were displaced by one shaft diameter or more (Table II). Soft-tissue injuries were classified according to Matter and Rittman (1977); 60 of our 97 cases had Grade II or Grade III injuries (Table III).

An urgent operation was performed in all cases. Soft tissue debridement was followed by copious irrigation 


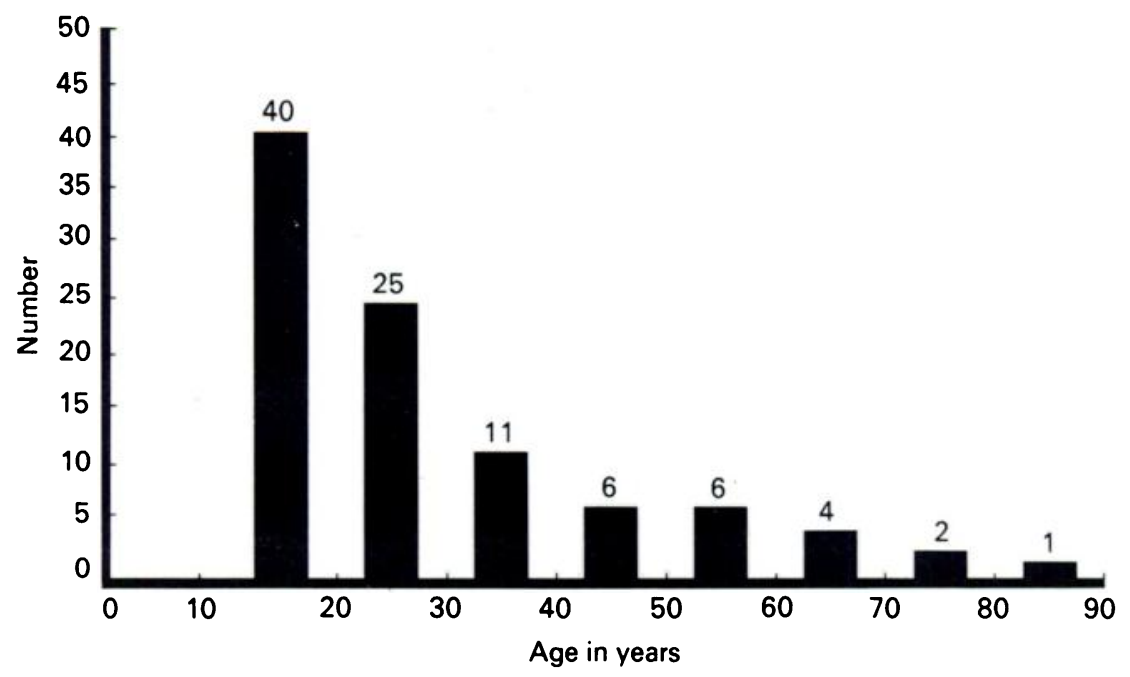

Fig. 1

Age distribution of 95 patients sustaining open tibial fractures.

Table III. Grading of the severity of the initial soft-tissue injury in 97 open tibial fractures (Matter and Rittman 1977)

\begin{tabular}{lll}
\hline Grade & Injury & $\begin{array}{l}\text { Number of } \\
\text { cases }\end{array}$ \\
\hline I & Puncture wound from within & 37 \\
II & $\begin{array}{l}\text { Trauma from without, producing a skin wound with } \\
\text { surrounding contusion and underlying muscle damage }\end{array}$ & 51 \\
III & $\begin{array}{l}\text { External trauma producing a severe wound with } \\
\text { an additional functional deficit due to damage } \\
\text { to vessels, nerves or entire muscle groups }\end{array}$ & 9 \\
\hline
\end{tabular}

and stable plate fixation using $\mathrm{AO}$ techniques and implants (Müller et al. 1979). In Toronto, the more severely compounded fractures were plated on their lateral aspect where muscle usually provided generous cover for the plate. In Nottingham, the subcutaneous medial border was preferred provided that adequate soft tissue cover was available. The more severely comminuted fractures in Nottingham were primarily grafted with cancellous bone at the time of the initial fixation, whereas similar fractures in Toronto received a delayed primary cancellous bone graft within six weeks of injury.

The surgical incision was closed primarily provided the resultant suture line was tension free, whereas the traumatic wound, if of any significant size, was left open.

After operation the leg was elevated with the ankle splinted in a plaster back slab to eliminate equinus deformity. After 24 hours the cast was removed at intervals to allow active and passive exercises to be supervised by a physiotherapist. All wound dressings were changed daily. In the case of Grade II and Grade III wounds, the initial dressing change was performed in the operating theatre on the second day after operation and if necessary a further debridement was performed under anaesthesia.

The hospital notes were reviewed for records of wound healing, time to full weight-bearing without support, and complications. Patients were questioned and examined at least one year after injury. The range of movement at the knee and ankle joints was measured with a goniometer and of the subtalar joint using a heel cup (McMaster 1976). Each range was expressed as a percentage of the measured movement of the same joint of the opposite leg. Alignment of the united fracture was measured on standard anteroposterior and lateral radiographs.

\section{RESULTS}

Wound healing. The times to wound healing are shown in Table IV. Twenty-seven wounds were closed by primary suture; 18 of these were of Grade I severity and all healed without complication within three weeks. The other nine wounds which were primarily sutured were of Grade II severity. Two of these developed an acute soft-tissue abscess which settled after surgical drainage, but in both cases healing was delayed beyond six weeks. Seventy wounds were left open, of which 35 healed by epithelialisation over granulation tissue, two were closed by delayed primary suture, 30 had split skin grafts and three were covered by a flap. 
In all, 62 wounds healed within three weeks and 26 between three and six weeks, whilst healing was delayed beyond six weeks in nine cases. Of these latter nine cases, five went on to develop a persistent discharging sinus. Fracture healing. Time to full weight-bearing is shown in Figure 2. Seventy-seven legs were fully weight-bearing without support by 30 weeks. Seven of the remaining 20 went on to spontaneous union without further treatment whilst 13 required further operations, including in 10 cases treatment for complications. All but one of the fractures united; one unfortunate 93-year-old man had established non-union and required amputation after failure of secondary external fixation and bone grafting.

Implant failure was seen in seven cases, all between 10 and 17 weeks after injury. Six were re-fixed, five with a plate and one with a nail, whilst one was treated conservatively in a plaster cast. In these seven cases, union was delayed beyond 30 weeks in four, one of which was infected, whilst the other three united within 26 weeks of injury.

Function. Twenty-five patients complained of aching pain at the fracture site but this was only an occasional problem in 20. Thirteen patients limped when they walked. Knee movement was impaired in eight cases, all of which had an associated ipsilateral knee or femoral injury; in only two was the range of movement reduced to less than $75 \%$ of that of the opposite knee. Ankle movement was full in 76 cases. Residual stiffness was recorded in 20 cases, 11 with over three-quarters of normal range and nine with less than three-quarters. Subtalar movement was full in 78 cases, more than threequarters range in 11 cases and less than three-quarters in seven cases.

A total of 11 patients developed significant stiffness in one or more of the knee, ankle or subtalar joints. Of 34 patients who developed complications, including the 16 who had secondary operations, only five developed significant stiffness in one or more joints.

\section{Complications}

Malunion. When measured on radiographs, 77 fractures had united in anatomical position whilst minor degrees of malalignment of less than $5^{\circ}$ in any plane were seen in 16 cases. Malunion of greater than $5^{\circ}$ occurred in three cases, one with a valgus angulation of $15^{\circ}$ following a plate failure treated in a cast and two with a $15^{\circ}$ recurvatum deformity.

Infection. Deep infection was defined as a persistent discharging sinus, not necessarily with sequestrum formation. It was seen in 10 cases $(10.3 \%)$. In relation to the severity of the initial wound, this included $5.4 \%$ of Grade I wounds, $7.8 \%$ of Grade II wounds and $44.4 \%$ of Grade III wounds. In three of these cases union was not delayed and the sinus healed after removal of the plate and debridement of the granulation tissue. In the other seven cases, union was delayed but all have since united after further operations. At last review, from six months

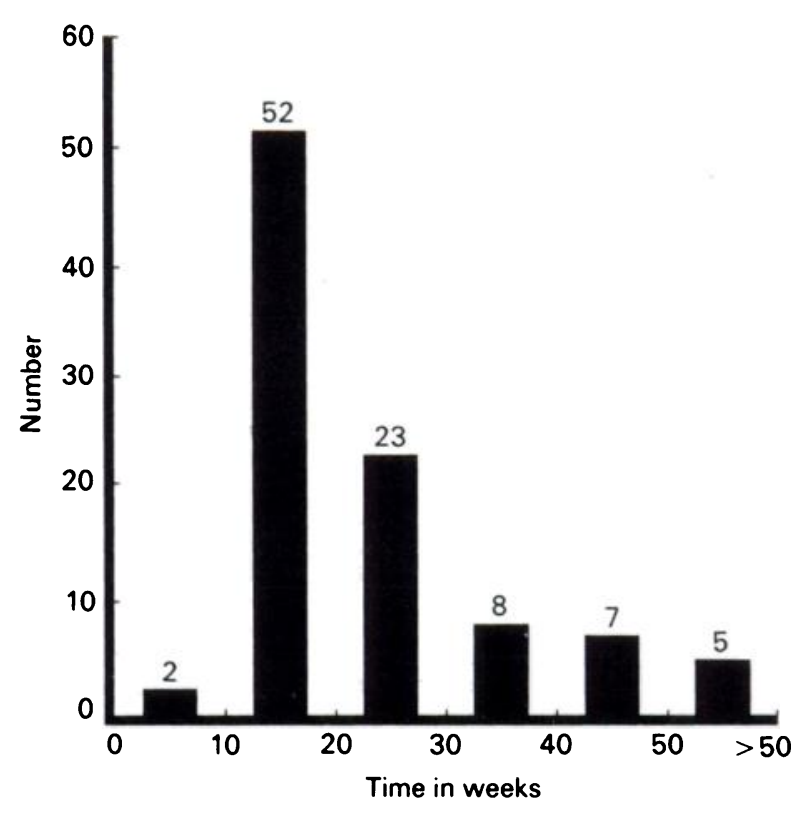

Fig. 2

Time to full weight-bearing in 97 open tibial fractures.

to two years after secondary surgery, all but one of the infections had cleared. One patient had an intermittent discharge from a sinus.

\section{DISCUSSION}

The mechanism of the injury which produces an open tibial fracture is of major clinical importance since it has a direct bearing on management and prognosis (Ellis 1958; Allum and Mowbray 1980). In civilian practice, these injuries usually follow high velocity trauma and, clinically, the high energy nature of the injury is shown by the severity of the wound, the comminution and displacement of the fracture and the frequent association with other injuries. When compared to low energy torsional fractures, these high energy injuries have an increased risk of complications and delay in healing (Nicoll 1964).

The timing of closure of the wound in open fractures remains controversial (Olerud, Karlstrom and Danckwardt-Lillieström 1978). The results of our series suggest that whilst primary suture of Grade I wounds is acceptable, it is better that larger wounds with skin loss are initially left open. It seems advisable that larger wounds be re-examined at a "second look" procedure under adequate anaesthesia and that skin cover be delayed until swelling has begun to settle and the microcirculation is restored. Long delays, however, should be avoided since in our series $55 \%$ of the cases in whom skin cover had not been attained within six weeks went on to develop deep-seated infection.

The internal fixation of open fractures has been unpopular on the grounds that a metallic foreign body 
may act as a nidus for infection - despite the fact that it is over 30 years since Hicks made the plea that metal per se did not cause infection (Hicks 1957). The view that the stability provided by internal fixation outweighs the disadvantages of the implantation of foreign material is supported by our results and those of other series (Ruedi, Webb and Allgöwer 1976; Christensen, Greiff and Rosendahl 1982; Oertli et al. 1984). The concept that bony stability is important in achieving early soft tissue healing and avoiding infection is further supported by the animal work of Friedrich and Klaue (1977) and more recently that of Worlock et al. (1987).

In recent years stable external fixation at a distance from the open fracture has become increasingly popular. External fixators are, however, cumbersome and have several disadvantages. They limit access to the wound, pin track sepsis is common, and the incidence of angular malunion is high (Edge and Denham 1981; Benum and Svenningsen 1982; Clifford, Lyons and Webb 1987). weight-bearing beyond 26 weeks or implant failure, occurred in 32 cases $(32.6 \%)$. Similar figures have been recorded after other forms of treatment (Nicoll 1964; Karlström and Olerud 1983), the relatively high incidence in these high energy fractures being determined by the severity of the initial trauma rather than the method of treatment. Angular malunion of over $5^{\circ}$ in any plane was seen in only $3.1 \%$. This compares well with the rates reported after conservative treatment (Nicoll 1964; Haines et al. 1984) or external fixation (Benum and Svenningsen 1982; Clifford, Lyons and Webb 1987).

In 1964 Nicoll stated, "There can only be one reason for submitting a patient to the additional hazards of surgery and that is to ensure a good functional result unlikely to be achieved by conservative treatment". In his series, $60 \%$ of the patients with moderate or severe wounds had significant joint stiffness. Treatment of open fractures conservatively in casts with early weightbearing has been reported by a number of authors but

Table IV. Time to healing of the wound in 97 open tibial fractures

\begin{tabular}{|c|c|c|c|c|c|c|c|c|c|}
\hline \multirow[b]{3}{*}{ Method of closure } & \multicolumn{9}{|c|}{ Severity of soft-tissue injury } \\
\hline & \multicolumn{3}{|l|}{ Grade I } & \multicolumn{3}{|l|}{ Grade II } & \multicolumn{3}{|l|}{ Grade III } \\
\hline & $<3$ weeks & 3 to 6 weeks & $>6$ weeks & $<3$ weeks & 3 to 6 weeks & $>6$ weeks & $<3$ weeks & 3 to 6 weeks & $>6$ weeks \\
\hline Primary suture & 18 & 0 & 0 & 6 & 1 & 2 & - & - & - \\
\hline Delayed primary suture & 1 & 0 & 0 & 1 & 0 & 0 & - & - & - \\
\hline Split skin graft & - & - & - & 18 & 4 & 1 & 0 & 4 & 3 \\
\hline Flap & - & - & - & 1 & - & - & 0 & 2 & 0 \\
\hline Granulation & 13 & 3 & 2 & 4 & 12 & 1 & - & - & - \\
\hline
\end{tabular}

The deep infection rate of $10.3 \%$ in our series is strikingly similar to that reported by others using the same method of treatment (Ruedi et al. 1976; Christensen et al. 1982; Oertli et al. 1984). In comparison, sepsis rates after conservative treatment vary from $3 \%$ to $23.8 \%$ (Brown and Urban 1969; Gallinaro, Crova and Denicolai 1973). Nicoll (1964) in his classic paper reported a $14.3 \%$ rate of infection in a group of 144 tibial fractures. Similarly, infection following external fixation is reported to range from $3.5 \%$ to $30 \%$ (Karlström and Olerud 1975; Edge and Denham 1981). Unfortunately, direct comparison of these series is not possible since in many reports the sepsis rate is not related to the severity of the original wound (Gustilo et al. 1969).

The assessment of time to bony union is notoriously difficult, particularly after rigid internal fixation, since movement at the fracture site is abolished and no callus is produced to be seen on the radiograph. In our series, evidence of progressing bony union was recorded as the time to full weight-bearing without support, with the consent of the attending surgeon and in the absence of any radiological or clinical signs of movement at the fracture site. Delayed union, defined as a delay to full only Brown and Urban (1969) claimed good functional results. Of the numerous papers reporting the results of external fixation, few give functional results although Behrens et al. (1983) found an average loss of joint motion of $30 \%$ whilst Karlström and Olerud (1983) reported $63 \%$ excellent or good function.

In our series, only $11.4 \%$ of patients developed significant stiffness in one or more of the knee, ankle or subtalar joints; these results compare with similar excellent functional results following the plating of open tibial fractures reported by Batten, Donaldson and Aldridge (1978) and Ruedi, Webb and Allgöwer (1976). Of particular importance, these figures also show that the final functional result is not compromised by the development of complications. Only five (14.7\%) of 34 patients with either complications or delayed union developed a significantly stiff joint. These results contrast strongly with Nicoll's $70 \%$ incidence of joint stiffness in his cases of delayed union and those of Tuite, Down and Calvert (1986) who found full ankle mobility in only six of 26 patients with a tibial non-union one year after treatment by a variety of means but all including cast immobilisation. 
Conclusions. We believe that our results show that the traditional fear of plating a Grade I or Grade II open fracture is unjustified. Provided initial selection and surgical techniques are performed with great care, the incidence of complications and, in particular, infection need be no higher that that which follows more conservative methods of treatment. Moreover, rigid fixation allows easy unencumbered access to the patient for treatment of his tibial wound, and by effecting anatomical reduction and allowing early mobilisation, it produces excellent results in terms of function.

This is particularly important in those patients with high energy injuries who, by the nature of their injury, are prone to complications and delayed union. They would otherwise be at risk of developing severe joint stiffness if immobilised in plaster for prolonged periods. However, plating is probably best avoided in Grade III open fractures since the incidence of infection is high. External fixation is an alternative method of bony stabilisation in these severe injuries, but whichever the chosen method, adequate wound debridement with early skin cover are essential to reduce septic complications.

We do not advocate that all open tibial fractures should be plated. Careful patient selection is important and only a surgeon experienced in the techniques of stable fixation and working in a fully equipped hospital should embark on such a procedure.

No benefits in any form have been received or will be received from a commercial party related directly or indirectly to the subject of this article.

\section{REFERENCES}

Allum RL, Mowbray MAS. A retrospective review of the healing of fractures of the shaft of the tibia with special reference to the mechanism of injury. Injury 1980;11:304-8.

Batten RL. Donaldson LJ, Aldridge MJ. Experience with the AO method in the treatment of 142 cases of fresh fracture of the tibial shaft treated in the UK. Injury 1978;10:108-14

Behrens F, Comfort TH, Searls K, Denis F, Young JT. Unilateral external fixation for severe open tibial fractures: preliminary report of a prospective study. Clin Orthop 1983;178:111-20.

Benum P, Svenningsen S. Tibial fractures treated with Hoffmann's external fixation: a comparative analysis of Hoffmann bilateral frames and the Vidal-Adrey double frame modification. Acta Orthop Scand 1982;53:471-6.

Brown PW, Urban JG. Early weight-bearing treatment of open fractures of the tibia: an end-result study of sixty-three cases. $J$ Bone Joint Surg [Am] 1969;51-A:59-75.

Christensen J, Greiff J, Rosendahl S. Fractures of the shaft of the tibia treated with AO-compression osteosynthesis. Injury 1982; $13: 307-14$

Clifford RP, Lyons TJ, Webb JK. Complications of external fixation of open fractures of the tibia. Injury 1987;18:174-6.

Edge AJ, Denham RA. External fixation for complicated tibial fractures. J Bone Joint Surg [Br] 1981 ;63-B:92-7.

Ellis $H$. The speed of healing after fracture of the tibial shaft. $J$ Bone Joint Surg $[B r] 1958 ; 40-B: 42-6$.

Friedrich B, Klaue P. Mechanical stability and post-traumatic osteitis an experimental evaluation of the relation between infection of bone and internal fixation. Injury 1977;9:23-9.

Gallinaro P, Crova M, Denicolai F. Complications in 64 open fractures of the tibia. Injury 1973;5:157-60.

Gustilo RB, Simpson L, Nixon R, Ruiz A, Indeck W. Analysis of 511 open fractures. Clin Orthop 1969;66:148-54.

Haines JF, Williams EA, Hargadon ES, Davies DRA. Is conservative treatment of displaced tibial shaft fractures justified? J Bone Joint Surg $[\mathrm{Br}] 1984 ; 66-\mathrm{B}: 84-8$.
Hicks JH. The relationship between metal and infection. JR Soc Med $1957: 50: 842-4$.

Hicks JH. Amputation in fractures of the tibia. J Bone Joint Surg [Br] 1964:46-B:388-92.

Karlström G, Olerud S. Percutaneous pin fixation of open tibial fractures: double-frame anchorage using the Vidal-Adrey method. $J$ Bone Joint Surg [Am] 1975;57-A :915-24.

Karlström G, Olerud S. External fixation of severe open tibial fractures with the Hoffmann frame. Clin Orthop 1983;180:68-77.

Matter P, Rittman W-W. The open fracture: assessment, surgical treatment and results. Berne, etc: Hans Huber, 1978.

McMaster M. Disability of the hindfoot after fracture of the tibial shaft. J Bone Joint Surg [Br] 1976;58-B:90-3.

Müller ME, Allgöwer M, Schneider R, Willenegger H. Manual of internal fixation: techniques recommended by the $A O$ Group. 2 nd ed Berlin etc: Springer-Verlag, 1979

Nicoll EA. Fractures of the tibial shaft: a survey of 705 cases. $J$ Bone Joint Surg [Br] 1964;46-B:373-87.

Oertli D, Matter P, Scharplatz D, Zehnder R. Evaluation of surgically treated shaft fractures: analysis of the Swiss AO/ASIF-documentation 1967-1980. Bulletin: Official publication of the Swiss Association for the study of internal fixation, 1984.

Olerud S, Karlstrom G, Danckwardt-Lillieström G. Treatment of open fractures of the tibia and ankle. Clin Orthop 1978;136:212-24.

Rittman WW, Perren SM. Cortical bone healing after internal fixation and infection. Berlin, etc: Springer-Verlag, 1974.

Ruedi T, Webb JK, Allgöwer M. Experience with the dynamic compression plate (DCP) in $\mathbf{4 1 8}$ recent fractures of the tibial shaft. Injury 1976;7:252-7.

Tuite J, Dowd GSE, Calvert PT. Functional results after prolonged delayed union of the tibial fractures. J Bone Joint Surg $[\mathrm{Br}]$ 1986;68-B :667.

Worlock PH, Slack RCB, Harvey L, Mawhinney RR. The effect of stability on the prevention of infection in experimental open fractures. SICOT Munich, 1987. Abstracts:110. 